\title{
Relationship Between Characteristics of Medications and Drug- Induced Liver Disease Phenotype and Outcome
}

\author{
Raj Vuppalanchi ${ }^{1}$, Raghavender Gotur ${ }^{1}$, K. Rajender Reddy ${ }^{2}$, Robert J. Fontana ${ }^{3}$, Marwan \\ Ghabril $^{1}$, Andrzej S. Kosinski ${ }^{4}$, Jiezhun $\mathrm{Gu}^{4}$, Jose Serrano ${ }^{5}$, and Naga Chalasani ${ }^{1}$ \\ ${ }^{1}$ Department of Medicine, Indiana University School of Medicine, Indianapolis, Indiana, USA \\ ${ }^{2}$ Department of Medicine, University of Pennsylvania, Philadelphia, Pennsylvania ${ }^{3}$ Department of \\ Internal Medicine, University of Michigan Medical School, Ann Arbor, Michigan ${ }^{4}$ Duke Clinical \\ Research Institute, Durham, North Carolina ${ }^{5}$ Liver Disease Research Branch, National Institute of \\ Diabetes and Digestive and Kidney Diseases, National Institutes of Health, Bethesda, Maryland
}

\begin{abstract}
Background \& Aims: It is not known if specific characteristics of medication are associated with type of drug-induced liver injury (DILI) or outcome. We examined the relationships among select characteristics of medications and DILI phenotype and outcome.
\end{abstract}

(C) 2013 The American Gastroenterological Association. Published by Elsevier Inc. All rights reserved

Author for Correspondence Naga Chalasani, MD, FACG David W. Crabb Professor \& Director Division of Gastroenterology and Hepatology Indiana University School of Medicine 1050 Wishard Boulevard, RG 4100 Indianapolis, IN 46202 Tel (317) 278-0414 Fax (317) 278-1949 nchalasa@iu.edu.

Author Contributions

Study concept and design: R.V., N.C., K.R.R.

Acquisition of data: R.G., R.V.

Analysis and interpretation of data: R.V., N.C.

Drafting the manuscript: R.V., N.C.

Critical revision of the manuscript for important intellectual content: R.V., N.C., K.R.R., M.G., R.J.F., J.S.

Statistical analysis: A.K., G.J.

Obtained funding: N.C.

Administrative, technical, or material support: N.C., A.K., G.J.

Study supervision: N.C., R.V.

Publisher's Disclaimer: This is a PDF file of an unedited manuscript that has been accepted for publication. As a service to our customers we are providing this early version of the manuscript. The manuscript will undergo copyediting, typesetting, and review of the resulting proof before it is published in its final citable form. Please note that during the production process errors may be discovered which could affect the content, and all legal disclaimers that apply to the journal pertain.

Disclosures

Dr. Vuppalanchi: Received compensation for consulting related to drug hepatotoxicity from BMS.

Dr. Gotur: No potential conflicts to declare

Dr. Reddy: Served on the advisory boards for Merck, Genentech-Roche, Gilead, BMS, Idenix, Vertex, Janssen, and Abbvie and has conducted research with Merck, Genentech-Roche, Gilead, BMS, Vertex, Janssen, and Abbvie.

Dr. Fontana: Received grant support from Gilead and Vertex and served as a paid consultant to Tibotec, Merck and GSK.

Dr. Ghabril: No potential conflicts to declare

Dr. Kosinski: No potential conflicts to declare

Dr. Gu: No potential conflicts to declare

Dr. Serrano: No potential conflicts to declare

Dr. Chalasani: Served as a paid consultant to Abbvie, Salix, BMS, Aegerion, Lilly and Merck in the past 12 months. Received grant support from Intercept, Cumberland, Gilead, Takeda and Enterome.

Writing Assistance

None 
Methods: We analyzed 383 cases of DILI caused by a single orally administered prescription agent from the DILI Network Prospective Study with causalities of definite, highly likely, or probable. Relationship of daily dosage ( $\geq 50 \mathrm{mg}$ vs. $\leq 49 \mathrm{mg}$ ), preponderance of hepatic metabolism ( $250 \%$ vs $<50 \%$ ), or Biopharmaceutics Drug Disposition Classification System (BDDCS) class (1-4, based on solubility and metabolism of the drug) were compared with clinical characteristics and outcomes.

Results: Compared to cases of DILI in the $<50 \mathrm{mg}$ /day group, those associated with daily dosages $\geq 50 \mathrm{mg}$ had shorter latency (median 38 days vs 56 days; $P=.03$ ) and a different biochemical pattern of liver injury $(P=.04)$; no differences in pattern of injury, recovery, severity, or outcome were observed. Patients with DILI caused by medications with or without preponderant hepatic metabolism did not differ in clinical characteristics or outcomes. Compared to other classes of BDDCS, DILI caused by BDDCS class 1 medications had significantly longer latency $(P<.001)$ and greater proportion of hepatocellular injury $(P=.001)$. However, peak liver biochemical values and patients' time to recovery, disease severity, and outcomes did not differ among the 4 BDDCS classes.

Conclusions: Characteristics of medications (dosage, hepatic metabolism, and solubility) are associated with features of DILI such as latency and pattern of liver injury, but not with recovery, severity, or outcome.

\section{Keywords}

DILIN; liver toxicity; overdose; side effect; ALT

\section{INTRODUCTION}

Idiosyncratic drug-induced liver injury (DILI) likely occurs due to complex interplay among host factors, environmental variables and the nature of the offending agent. ${ }^{1}$ Research efforts over the last decade have therefore focused primarily on the understanding of the genetic factors that increase an individual's susceptibility to DILI. ${ }^{2,}{ }^{3}$ However, medication characteristics such as daily dose administered and their metabolism profile are starting to emerge as potential risk factors for DILI. ${ }^{4-7}$

It was initially pointed out by J. Uetrecht that drugs given at a daily dose of $10 \mathrm{mg}$ or less are rarely if ever associated with a high incidence of DILI and majority of the drugs that were either withdrawn from the market or received a black box warning due to hepatotoxicity were prescribed at daily doses greater than $50 \mathrm{mg} .{ }^{8}$ Lammert et al. reported a statistically significant relationship between daily dose of oral medicines and reports of liver failure, liver transplantation and death due to DILI. ${ }^{6}$ Lammert et al. also reported that compounds with $>50 \%$ hepatic metabolism had significantly higher frequency of ALT $>3 \mathrm{X}$ ULN, liver failure and fatal DILI. ${ }^{4}$ Recently, Chen et al. suggested a combined effect of daily dosage of $>100 \mathrm{mg}$ and high lipophilicity on the risk of DILI among medications approved by the Food and Drug Administration. ${ }^{5}$

Drugs with higher lipophilicity resulting in increased permeability and uptake by hepatocytes may undergo greater biotransformation leading to toxic metabolites and 
heightened susceptibility to DILI. ${ }^{7}{ }^{9}$ Conversely, drugs with low lipophilicity have low permeability, undergo less hepatic metabolism and may be at lower risk for causing DILI as they are primarily eliminated unchanged into the urine and bile. ${ }^{7,9}$ However, some drugs (cefadroxil, cephradine, levofloxacin, loracerbef, ofloxacin, sotalol and pregabalin) classified as having low permeability exhibit high absorption $\searrow 00 \%$ due to presence of intestinal drug transporters. ${ }^{10}$ By evaluating metabolism, not permeability or lipophilicity, drugs can be categorized into four classes according to their solubility and metabolism using the Biopharmaceutics Drug Disposition Classification System (BDDCS) classification: Class 1 (High solubility- Extensive metabolism), Class 2 (Low solubility- Extensive metabolism), Class 3 (High Solubility- Poor metabolism), and Class 4 (Low solubility Poor Metabolism). ${ }^{11-13}$ The current study investigated the relationship between DILI phenotypic characteristics and select drug properties such as a) daily dosage: $250 \mathrm{mg} \mathrm{b}$ ) predominant hepatic metabolism ( $>50 \%)$ and c) BDDCS classes 1-4.

\section{METHODS}

We extracted data from the U.S. DILIN prospective study database with the following eligibility criteria: (a) Cases that have been causality adjudicated with a DILIN causality score probable or higher as described previously ${ }^{16,17}$ and (b) DILI caused by single oral prescription agent taken daily. A DILIN severity score was assigned according to a previously published scale from 1 (mild with serum total bilirubin $<2.5 \mathrm{mg} / \mathrm{dL}$ ) to 5 (death or liver transplantation). ${ }^{14,15}$ Information regarding the drug dosage administered to the patient was extracted from the DILIN database (DILIMED). Drugs were categorized based on daily dosage into those with and without appreciable hepatic metabolism based on information within drug's approved package insert, DrugBank (www.drugbank.ca) or DailyMed (dailymed.nlm.nih.gov). BDDCS classification of the drugs was obtained from previously published literature. ${ }^{11}$ By evaluating metabolism, not permeability, BDDCS is not subject to variability due to transporter effects. ${ }^{11,12}$ Demographic, biochemical and clinical outcomes were extracted and analyses were performed on the following variables (a) latency (time from drug exposure to DILI onset), (b) time to peak values for total bilirubin, (c) time to recovery (peak to 50\% reduction in total bilirubin), (d) DILIN severity score, and (e) outcomes (hospitalization, liver related death and transplant).

The data analyses were performed at the Duke Clinical Research Institute, the data coordinating center of the DILIN. SAS v 9.2 was used to aid all analyses. Continuous variables were summarized with mean and standard deviation or median and interquartile range (IQR). Categorical data were expressed as counts and proportions. Fisher's exact test was used to analyze differences between groups for the categorical data and differences between groups for continuous variables were assessed with a non-parametric test (Wilcoxon test for two groups or Kruskal-Wallis one-way analysis of variance for more than two groups). P-values less than 0.05 were considered statistically significant. There was no adjustment made for multiplicity of comparisons. The authors had access to the study data and have reviewed and approved the final manuscript. 


\section{RESULTS}

A total of 1083 DILI subjects enrolled up to March 2012 were screened to identify 383 cases that met the eligibility criteria (Fig 1). A total of 107 drugs were responsible for these DILI episodes. We could not obtain the details of hepatic metabolism on 3 (febuxostat, investigational drug, ranitidine) and the specifics of BDDCS in 8 drugs (benzonatate, deferasirox, flavocoxid, investigational drug, phentermine, regorafenib, salsalate, and thiamazole). The mean age of the patients in the study cohort was $50 \pm 18$ years with $63 \%$ women and $79 \%$ Caucasian.

\section{Relationship between drug dose and DILI phenotype and outcomes}

Episodes of DILI due to drugs with daily dosage $\geq 50 \mathrm{mg}$ had significantly shorter latency period as compared to those who received $\leq 49 \mathrm{mg}$ per day [38 (20-96) vs.56 (30-208) days, $P=.03]$. The pattern of liver injury (Cholestatic/Mixed/Hepatocellular) at onset was also significantly different between two dosage groups $(P=.04)$, with a greater proportion of cholestatic liver injury in $\leq 49 \mathrm{mg}$ per day. However, no other significant differences were noted between the groups with regard to peak values of liver biochemistries, time to peak, and time to recovery (Table 1 ). The DILIN severity scores were not significantly different based on dose classification $(P=.3)$. Similarly, clinical outcomes such as hospitalization rate, liver-related death and liver transplantation rate were not different between two groups (Table 1).

\section{Relationship between drug metabolism and DILI phenotype and outcomes}

In the current cohort, a higher number of cases had DILI from drugs that underwent significant hepatic metabolism ( $\mathrm{n}=305)$ compared to those without hepatic metabolism $(n=71)$. The two groups otherwise did not differ with regard to variables such as latency, pattern of liver injury, time to peak, and time to recovery. The DILIN severity scores were not significantly different based on hepatic metabolism classification $(P=.3)$. Outcomes such as hospitalization rate (55\% vs. $44 \%, P=.3)$, liver-related death $(2 \%$ vs. $5.6 \%, P=.7)$ and liver transplant (3.3\% vs. $1.4 \%, P=.7$ ) were not different between two groups (Table 1 ).

\section{Relationship of BDDCS classification with DILI phenotype and outcomes}

A total of 99 drugs belonging to BDDCS Classes 1 through 4 were responsible for these DILI episodes (Table 2). The distribution of cases belonging to each BDDCS group was different with underrepresentation of DILI cases caused by BDDCS Class 4 agents. Four compounds (ciprofloxacin, nitrofurantoin, cefdinir and levonorgestrel//ethinylestradiol) accounted for all cases of DILI belonging to BDDCS Class 4 (Table 2). DILI cases from drugs belonging to Class 4 differed from other groups in having a significantly lower percentage of jaundiced patients $(P<0.001)$, absolute eosinophilia $>500 / \mathrm{uL}(P=.008)$ with lower peak ALT $(\mathrm{p}=0.001)$ and AST $(P<0.001)$. The groups differed significantly with regard to latency period with Class 1 having the longest latency period $(P<0.001)$ (Table 1$)$. The pattern of liver injury at onset was significantly different between the groups $(P<0.001)$ with Class 1 having the highest proportion of HC pattern (76\%). However, no significant differences were noted between the groups with regard to time to peak total bilirubin and time to recovery. Hospitalization rate was significantly different among the groups $(P=.01)$ 
with Class 4 having the lowest rates at $45 \%$ (Table 1). However, outcomes such as liver related death $(P=.1)$ and transplantation rate $(P=.3)$ were not different (Table 1$)$.

\section{DISCUSSION}

Although prior studies have suggested a relationship between drug characteristics and their propensity to cause DILI, data regarding drug characteristics and DILI phenotype are lacking. In the current study, we leveraged the unique features of DILIN database to examine the relationships among drug characteristics and DILI phenotype and outcomes. The current observations of shorter latency with daily dosage of $\geq 50 \mathrm{mg}$ and a higher peak ALT with drugs that undergo hepatic metabolism demonstrate the importance of the intrinsic drug properties as a potential factor for the development of a DILI event. These findings also suggest that a threshold level of parent drug, metabolite, and / or adducts is a prerequisite for the DILI event. However, lack of any significant differences in the clinical outcomes supports the current understanding that the mechanism of injury and subsequent recovery may be predominantly mediated by the host immune response or host susceptibility due to genetic or acquired inability to detoxify hepatotoxic drug intermediates. ${ }^{1,16,17}$ Further studies are needed to examine how these properties influence mechanisms involved in DILI such as CYP bioactivation reactions, covalent binding, or mitochondrial toxicity. ${ }^{18,} 19$

Our examination of the relationship among drug properties such as aqueous solubility / gastrointestinal permeability using BDDCS classification ${ }^{20,21}$ and DILI phenotype or outcomes led to some novel observations. First, drugs belonging to Class 4 (cefdinir, ciprofloxacin, nitrofurantoin, and levonorgestrel with ethinylestradiol) were incriminated in lower percentage of DILI patients, possibly because BDDCS class 4 drugs are underrepresented in orally approved drugs. These BDDCS class 4 drugs were associated with a significantly lower peak serum aminotransferase levels presumably due to their low permeability and solubility resulting in reduced uptake and lower hepatic biotransformation. A detailed review of these cases showed instances where prolonged exposure of the drug occurred (in some cases of nitrofurantoin exposure occurred for several years) before the DILI episode occurred. Second, the current study identified $81 \%$ of the drugs causing DILI episodes as undergoing extensive hepatic metabolism, suggesting that a reactive metabolite intermediate, rather that the native drug may be responsible for the development of a DILI event, possibly through the formation of adduct complexes, acting as neoantigens.

Autoimmune DILI is often associated with presence of serum autoantibodies directed against hepatic cytochrome $\mathrm{P} 450$ s or other hepatic proteins. ${ }^{22}$ The covalent binding of the drug or reactive metabolite to liver microsomal proteins results in formation of a neoantigen with subsequent injury from immune response. ${ }^{23,} 24$ It is thus plausible that drugs that belong to BDCSS class 1 and 2 (Extensive metabolism) may be at increased risk of causing autoimmune DILI. In the current study, we observed that several drugs that have previously been implicated to cause autoimmune DILI ${ }^{22}$ belonged to BDCSS Class 1 (hydralazine, minocycline, propylthiouracil, methylphenidate and diclofenac) and 2 (atorvastatin, imatinib, fenofibrate and terbinafine) (Table 2). However, two drugs with definite association with autoimmune DILI i.e., methyldopa (BDCSS Class 3) and nitrofurantoin 
(BDCSS Class 4) diverge from this pattern suggesting additional role of host related factors as being critical for a DILI event.

Lastly, the unique strengths of the DILIN cohort such as the ability to examine DILI cases with strong causality $(1,2$, or 3 ) and availability of prospectively captured DILI phenotype and outcomes allowed us to perform the current study. The pitfalls common in the literature such as DILI case definition and causality adjudication are minimized in the DILIN prospective study because of its study design. ${ }^{14,15,25}$ The current study failed to find any significant differences in clinic outcomes based on daily dosage in contrast to the earlier study by Lammert et al. who evaluated the Swedish registry. It is likely that these differences could be related to the DILIN registry prospective protocol and the current study design that included only DILI cases from single agent and with causality limited to the scores of 1,2 or 3 . It is also possible that lack of relationship between drug metabolism as well as of BDDCS classification with clinical outcomes might be due to lack of adequate sample size.

In summary, drug characteristics such as daily dosage $250 \mathrm{mg}$ and BDDCS Class 1 are related to select aspects of DILI phenotype. However, the severity of liver disease and outcomes are not associated with drug characteristics. We speculate that DILI outcomes may be more related to host response rather than drug characteristics.

\section{Acknowledgments}

Grant Support: The U.S. Drug Induced Liver Injury Network (DILIN) is supported by the National Institute of Diabetes and Digestive and Kidney Diseases under the following cooperative agreements: 1U01DK065021, U01DK065193, 1U01DK065201, 1U01DK065193, 1U01DK065184, 1U01DK065211, 1U01DK065238, and 1U01DK065176.

\section{Abbreviations}

BDDCS: $\quad$ Biopharmaceutics Drug Disposition Classification System

DILI: $\quad$ Drug-Induced Liver Injury

DILIN: $\quad$ Drug-Induced Liver Injury Network

ULN: $\quad$ Upper Limit of Normal

\section{REFERENCES}

1. Tujios S, Fontana RJ. Mechanisms of drug-induced liver injury: from bedside to bench. Nat Rev Gastroenterol Hepatol. 2011; 8:202-11. [PubMed: 21386809]

2. Monshi MM, Faulkner L, Gibson A, et al. Human leukocyte antigen (HLA)-B*57:01-restricted activation of drug-specific $\mathrm{T}$ cells provides the immunological basis for flucloxacillin-induced liver injury. Hepatology. 2013; 57:727-39. [PubMed: 22987284]

3. Urban TJ, Shen Y, Stolz A, et al. Limited contribution of common genetic variants to risk for liver injury due to a variety of drugs. Pharmacogenet Genomics. 2012; 22:784-95. [PubMed: 22968431]

4. Lammert C, Bjornsson E, Niklasson A, et al. Oral medications with significant hepatic metabolism at higher risk for hepatic adverse events. Hepatology. 2010; 51:615-20. [PubMed: 19839004] 
5. Chen M, Borlak J, Tong W. High lipophilicity and high daily dose of oral medications are associated with significant risk for drug-induced liver injury. Hepatology. 2013; 58:388-96. [PubMed: 23258593]

6. Lammert C, Einarsson S, Saha C, et al. Relationship between daily dose of oral medications and idiosyncratic drug-induced liver injury: search for signals. Hepatology. 2008; 47:2003-9. [PubMed: 18454504]

7. Hughes JD, Blagg J, Price DA, et al. Physiochemical drug properties associated with in vivo toxicological outcomes. Bioorg Med Chem Lett. 2008; 18:4872-5. [PubMed: 18691886]

8. Uetrecht J. Idiosyncratic drug reactions: current understanding. Annu Rev Pharmacol Toxicol. 2007; 47:513-39. [PubMed: 16879083]

9. Kaplowitz N. Avoiding idiosyncratic DILI: two is better than one. Hepatology. 2013; 58:15-7. [PubMed: 23390057]

10. Chen ML, Yu L. The use of drug metabolism for prediction of intestinal permeability (dagger). Mol Pharm. 2009; 6:74-81. [PubMed: 19132929]

11. Benet LZ, Broccatelli F, Oprea TI. BDDCS applied to over 900 drugs. AAPS J. 2011; 13:519-47. [PubMed: 21818695]

12. Benet LZ. The role of BCS (biopharmaceutics classification system) and BDDCS (biopharmaceutics drug disposition classification system) in drug development. J Pharm Sci. 2013; 102:34-42. [PubMed: 23147500]

13. Benet LZ, Amidon GL, Barends DM, et al. The use of BDDCS in classifying the permeability of marketed drugs. Pharm Res. 2008; 25:483-8. [PubMed: 18236138]

14. Fontana RJ, Watkins PB, Bonkovsky HL, et al. Drug-Induced Liver Injury Network (DILIN) prospective study: rationale, design and conduct. Drug Saf. 2009; 32:55-68. [PubMed: 19132805]

15. Chalasani N, Fontana RJ, Bonkovsky HL, et al. Causes, clinical features, and outcomes from a prospective study of drug-induced liver injury in the United States. Gastroenterology. 2008; 135:1924-34. 1934 e1-4. [PubMed: 18955056]

16. Lucena MI, Molokhia M, Shen Y, et al. Susceptibility to amoxicillin-clavulanate-induced liver injury is influenced by multiple HLA class I and II alleles. Gastroenterology. 2011; 141:338-47. [PubMed: 21570397]

17. Daly AK, Donaldson PT, Bhatnagar P, et al. HLA-B*5701 genotype is a major determinant of drug-induced liver injury due to flucloxacillin. Nat Genet. 2009; 41:816-9. [PubMed: 19483685]

18. Metushi IG, Cai P, Zhu X, et al. A fresh look at the mechanism of isoniazid-induced hepatotoxicity. Clin Pharmacol Ther. 2011; 89:911-4. [PubMed: 21412230]

19. Alfirevic A, Pirmohamed M. Predictive genetic testing for drug-induced liver injury: considerations of clinical utility. Clin Pharmacol Ther. 2012; 92:376-80. [PubMed: 22850601]

20. Benet LZ. Predicting drug disposition via application of a Biopharmaceutics Drug Disposition Classification System. Basic Clin Pharmacol Toxicol. 2010; 106:162-7. [PubMed: 20002064]

21. Wu CY, Benet LZ. Predicting drug disposition via application of BCS: transport/absorption/ elimination interplay and development of a biopharmaceutics drug disposition classification system. Pharm Res. 2005; 22:11-23. [PubMed: 15771225]

22. Czaja AJ. Drug-induced autoimmune-like hepatitis. Dig Dis Sci. 2011; 56:958-76. [PubMed: 21327704]

23. Beaune PH, Bourdi M. Autoantibodies against cytochromes P-450 in drug-induced autoimmune hepatitis. Ann N Y Acad Sci. 1993; 685:641-5. [PubMed: 8363271]

24. Beaune PH, Lecoeur S, Bourdi M, et al. Anti-cytochrome P450 autoantibodies in drug-induced disease. Eur J Haematol Suppl. 1996; 60:89-92. [PubMed: 8987248]

25. Aithal GP, Watkins PB, Andrade RJ, et al. Case definition and phenotype standardization in druginduced liver injury. Clin Pharmacol Ther. 2011; 89:806-15. [PubMed: 21544079] 


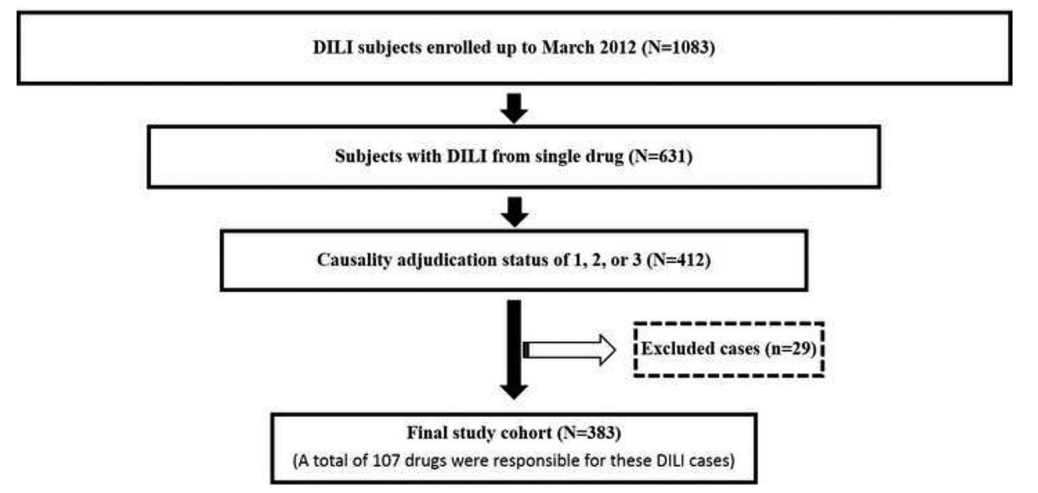

Figure 1.

Flowchart describing the selection of the study population. A total of 1083 subjects with drug induced liver injury (DILI) were enrolled up to March 2012. Among these, 631 subjects had DILI from a single drug. After causality adjudication, there were 412 subjects with adjudication status of definite, highly likely, and probable (1, 2 or 3). An additional 29 cases were excluded due to unknown dosage, drug start/stop date or mode of administration. The final study cohort consisted of 383 DILI cases resulting from 107 different drugs satisfied the study inclusion criteria: (a) DILI occurring from a single agent, (b) administered orally, (c) known daily dosage, and (d) causality of 1, 2 or 3. 


\section{Table 1}

Relationship between drug characteristics and the DILI phenotype and outcomes $(\mathrm{N}=383)$.

\begin{tabular}{|c|c|c|c|c|c|c|c|}
\hline & $\begin{array}{c}\text { Latency } \\
\text { (days) }\end{array}$ & $\begin{array}{c}\text { Pattern of liver } \\
\text { injury at } \\
\text { onset }(\mathrm{C} / \mathrm{M} / \mathrm{HC}, \\
\%)\end{array}$ & $\begin{array}{c}\text { Time to Peak } \\
\text { (days) }\end{array}$ & $\begin{array}{l}\text { Time to } \\
\text { Recovery } \\
\text { (days) }\end{array}$ & $\begin{array}{c}\text { Hospitalization } \\
(\%)\end{array}$ & $\begin{array}{c}\text { Liver } \\
\text { related } \\
\text { Death }(\%)\end{array}$ & $\begin{array}{c}\text { Transplant } \\
(\%)\end{array}$ \\
\hline \multicolumn{8}{|l|}{ Daily dose } \\
\hline$\geq 50 \mathrm{mg}(\mathrm{n}=324)$ & $38(20-96)$ & $21 / 25 / 54$ & $8(2-15)$ & $31(13-51)$ & 52 & 2.8 & 3.4 \\
\hline \multirow[t]{2}{*}{$\leq 49 \mathrm{mg}(\mathrm{n}=53)$} & $56(30-208)$ & $32 / 11 / 57$ & $10(4-22)$ & $36(12-70)$ & 62 & 1.9 & 0 \\
\hline & $(\mathrm{p}=0.03)$ & $(\mathrm{p}=0.040)$ & $(\mathrm{p}=0.1)$ & $(\mathrm{p}=0.3)$ & $(\mathrm{p}=0.2)$ & $(\mathrm{p}=1.0)$ & $(\mathrm{p}=0.4)$ \\
\hline \multicolumn{8}{|c|}{ Hepatic Metabolism } \\
\hline Yes $(n=305)$ & $42(25-100)$ & $23 / 24 / 53$ & $8(2-16)$ & $33(13-56)$ & 55 & 2.0 & 3.3 \\
\hline \multirow[t]{2}{*}{ No $(n=71)$} & $34(16-101)$ & $23 / 21 / 56$ & $7(2-17)$ & $31(12-45)$ & 47 & 5.6 & 1.4 \\
\hline & $(\mathrm{p}=0.3)$ & $(\mathrm{p}=0.9)$ & $(\mathrm{p}=0.9)$ & $(\mathrm{p}=0.3)$ & $(\mathrm{p}=0.2)$ & $(\mathrm{p}=0.1)$ & $(\mathrm{p}=0.7)$ \\
\hline \multicolumn{8}{|c|}{ Biopharmaceutics Drug Disposition Class } \\
\hline Class $1(n=118)$ & $81(43-214)$ & $12 / 12 / 76$ & $7(2-14)$ & $27(12-44)$ & 53 & 2.5 & 5.1 \\
\hline Class $2(n=96)$ & $35(43-214)$ & $25 / 29 / 46$ & $10(3-23)$ & $31(10-55)$ & 68 & 2.1 & 1.0 \\
\hline Class $3(n=112)$ & $28(16-44)$ & $32 / 29 / 39$ & $7(1-13)$ & $38(17-53)$ & 46 & 0.9 & 1.8 \\
\hline \multirow[t]{2}{*}{ Class $4(n=38)$} & $38(15-568)$ & $26 / 24 / 50$ & $11(3-22)$ & $25(7-49)$ & 45 & 7.9 & 2.6 \\
\hline & $(\mathrm{p}<0.001)$ & $(\mathrm{p}<0.001)$ & $(\mathrm{p}=0.1)$ & $(\mathrm{p}=0.1)$ & $(\mathrm{p}=0.01)$ & $(\mathrm{p}=0.1)$ & $(\mathrm{p}=0.3)$ \\
\hline
\end{tabular}

All values are expressed as median (IQR) unless otherwise expressed. R ratio was calculated by dividing the ALT by the ALP from initial blood test, using multiples of the ULN for both values. $\mathrm{R} \leq 2$ Cholestatic (C) pattern of DILI, $2<\mathrm{R}<5$ Mixed (M) pattern of DILI, or $\mathrm{R}>5$ : Hepatocellular (HC) pattern of DILI. 


\section{Table 2}

List of drugs implicated in the DILI episode. Drugs arranged as per Biopharmaceutics Drug Disposition Classification System (BDDCS) class. A total of 99 drugs with BDDCS class of 1, 2, 3 or 4 were responsible for 372 cases of DILI. Drugs that are underlined have been associated with autoimmune DILI phenotype.

\begin{tabular}{|c|c|c|c|}
\hline $\begin{array}{c}\text { Class 1 } \\
\begin{array}{c}\text { (High solubility - Extensive } \\
\text { metabolism }) \\
(\mathbf{n}=118)\end{array}\end{array}$ & $\begin{array}{c}\text { Class } 2 \\
\begin{array}{c}\text { (Low solubility }- \text { Extensive } \\
\text { metabolism) } \\
(\mathbf{n}=99)\end{array}\end{array}$ & $\begin{array}{c}\text { Class } 3 \\
\begin{array}{c}\text { (High solubility - Poor } \\
\text { metabolism) } \\
(\mathbf{n}=115)\end{array}\end{array}$ & $\begin{array}{c}\text { Class } 4 \\
\begin{array}{c}\text { Low solubility - Poor } \\
\text { metabolism }) \\
(n=40)\end{array}\end{array}$ \\
\hline ALFUZOSIN (n=1) & ACITRETIN (n=3) & AMOXICILLIN (n=6) & CEFDINIR $(\mathrm{n}=1)$ \\
\hline ALISKIREN ( $\mathrm{n}=1)$ & ALLOPURINOL ( $\mathrm{n}=2)$ & AMOXICILLIN & CIPROFLOXACIN $(\mathrm{n}=11)$ \\
\hline ATOMOXETINE (n=3) & AMIODARONE $(\mathrm{n}=4)$ & W/CLAVULANIC ACID & LEVONORGESTREL \\
\hline AZATHIOPRINE (n=4) & ATORVASTATIN $(\mathrm{n}=4)$ & $(\mathrm{n}=61)$ & W/ETHINYLESTRADIOL \\
\hline BUPROPION (n=3) & BOSENTAN $(n=1)$ & ATENOLOL $(\mathrm{n}=1)$ & $(\mathrm{n}=1)$ \\
\hline CLINDAMYCIN $(\mathrm{n}=1)$ & CARBAMAZEPINE $(\mathrm{n}=2)$ & AZITHROMYCIN (n=4) & NITROFURANTOIN \\
\hline CYCLOPHOSPHAMIDE (n=2) & CELECOXIB $(\mathrm{n}=2)$ & BENAZEPRIL W/HCTZ & $(\mathrm{n}=27)$ \\
\hline DANTROLENE $(\mathrm{n}=1)$ & DISULFIRAM (n=2) & $(\mathrm{n}=1)$ & \\
\hline DICLOFENAC $(\mathrm{n}=9)$ & DRONEDARONE (n=2) & CEFACLOR $(\mathrm{n}=1)$ & \\
\hline DULOXETINE $(\mathrm{n}=6)$ & DROSPIRENONE & CEFADROXIL $(\mathrm{n}=1)$ & \\
\hline ESCITALOPRAM $(\mathrm{n}=1)$ & W/ETHINYLESTRADIOL $(\mathrm{n}=1)$ & CEFALEXIN(n=1) & \\
\hline ESTRADIOL (n=1) & ETODOLAC $(\mathrm{n}=2)$ & CEFUROXIME $(\mathrm{n}=1)$ & \\
\hline ETHOSUXIMIDE $(\mathrm{n}=1)$ & EZETIMIBE W/SIMVASTATIN & DOXYCYCLINE $(\mathrm{n}=4)$ & \\
\hline FLUOXETINE $(\mathrm{n}=1)$ & $(\mathrm{n}=2)$ & ERYTHROMYCIN (n=2) & \\
\hline FLUVASTATIN $(\mathrm{n}=1)$ & FEBUXOSTAT $(\mathrm{n}=1)$ & FLUCONAZOLE $(\mathrm{n}=2)$ & \\
\hline HYDRALAZINE $(\mathrm{n}=4)$ & FENOFIBRATE $(\mathrm{n}=2)$ & GABAPENTIN $(\mathrm{n}=1)$ & \\
\hline ISONIAZID (n=32) & IMATINIB $(\mathrm{n}=3)$ & LEVOFLOXACIN (n=4) & \\
\hline LABETALOL $(\mathrm{n}=1)$ & ITRACONAZOLE $(\mathrm{n}=1)$ & LISINOPRIL (n=2) & \\
\hline LETROZOLE $(\mathrm{n}=1)$ & LAMOTRIGINE (n=5) & METHOTREXATE $(\mathrm{n}=1)$ & \\
\hline METHYLPHENIDATE $(\mathrm{n}=1)$ & LANSOPRAZOLE $(\mathrm{n}=1)$ & $\underline{\text { METHYLDOPA }(\mathrm{n}=8)}$ & \\
\hline MINOCYCLINE $(\mathrm{n}=22)$ & LAPATINIB $(\mathrm{n}=1)$ & METOCLOPRAMIDE & \\
\hline NICOTINIC ACID (n=2) & LEFLUNOMIDE (n=2) & $(\mathrm{n}=1)$ & \\
\hline PROMETHAZINE $(\mathrm{n}=1)$ & MELOXICAM (n=2) & MOXIFLOXACIN (n=2) & \\
\hline PROPYLTHIOURACIL (n=2) & MERCAPTOPURINE (n=5) & PENICILLAMINE (n=1) & \\
\hline PYRAZINAMIDE (n=1) & MESALAZINE $(\mathrm{n}=1)$ & PRAVASTATIN $(\mathrm{n}=1)$ & \\
\hline QUETIAPINE $(\mathrm{n}=1)$ & METAXALONE $(\mathrm{n}=1)$ & RANITIDINE (n=2) & \\
\hline SERTRALINE $(\mathrm{n}=1)$ & MONTELUKAST (n=2) & ROSUVASTATIN (n=4) & \\
\hline TAMOXIFEN $(\mathrm{n}=4)$ & NEVIRAPINE (n=2) & TOPIRAMATE $(\mathrm{n}=3$ ) & \\
\hline VALACICLOVIR (n=1) & OLANZAPINE (n=1) & & \\
\hline VALPROIC ACID (n=5) & OXAPROZIN $(\mathrm{n}=1)$ & & \\
\hline \multirow[t]{5}{*}{ VERAPAMIL $(\mathrm{n}=3)$} & PHENYTOIN (n=8) & & \\
\hline & PRASUGREL $(\mathrm{n}=1)$ & & \\
\hline & QUINAPRIL (n=1) & & \\
\hline & SIMVASTATIN $(\mathrm{n}=4)$ & & \\
\hline & SULFASALAZINE $(\mathrm{n}=1)$ & & \\
\hline
\end{tabular}




\begin{tabular}{|c|c|c|c|}
\hline $\begin{array}{c}\text { Class 1 } \\
\begin{array}{c}\text { (High solubility - Extensive } \\
\text { metabolism) } \\
(\mathbf{n}=\mathbf{1 1 8})\end{array}\end{array}$ & $\begin{array}{c}\text { Class } 2 \\
\begin{array}{c}\text { (Low solubility - Extensive } \\
\text { metabolism) } \\
(\mathbf{n}=99)\end{array}\end{array}$ & $\begin{array}{c}\text { Class } 3 \\
\begin{array}{c}\text { (High solubility - Poor } \\
\text { metabolism) } \\
(\mathbf{n}=115)\end{array}\end{array}$ & $\begin{array}{c}\text { Class } 4 \\
\begin{array}{c}\text { Low solubility - Poor } \\
\text { metabolism }) \\
(n=40)\end{array}\end{array}$ \\
\hline & SULFAMETHOXAZOLE & & \\
\hline & W/TRIMETHOPRIM (n=12) & & \\
\hline & TACROLIMUS $(\mathrm{n}=1)$ & & \\
\hline & TELITHROMYCIN ( $\mathrm{n}=5$ ) & & \\
\hline & TEMOZOLOMIDE $(\mathrm{n}=1)$ & & \\
\hline & TERBINAFINE $(\mathrm{n}=5)$ & & \\
\hline & THALIDOMIDE $(\mathrm{n}=1)$ & & \\
\hline & VORICONAZOLE $(\mathrm{n}=1)$ & & \\
\hline
\end{tabular}

Solubility refers to solubility in water: High solubility compound at the highest marketed dose strength would be soluble in $250 \mathrm{~mL}$ of water over the $\mathrm{pH}$ range of $1-7.5$ at $37^{\circ} \mathrm{C}$. 